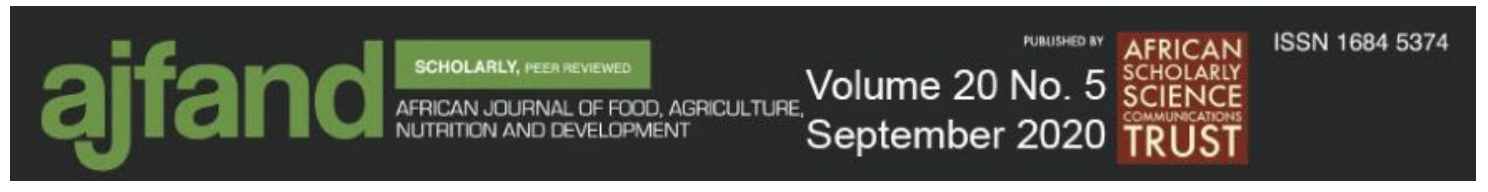

Afr. J. Food Agric. Nutr. Dev. 2020; 20(5): 16403-16419

https://doi.org/10.18697/ajfand.93.19510

\title{
ACCESSIBILITY, AVAILABILITY AND CONSUMPTION \\ OF BAOBAB DURING FOOD EMERGENCIES \\ IN KITUI AND KILIFI COUNTIES IN KENYA
}

Wanjeri $\mathrm{N}^{2 *}$, Owino $\mathrm{W}^{1}$, Kyallo $\mathrm{F}^{2}$, Habte $\mathrm{TY}^{3}$ and MB Krawinkel ${ }^{3}$

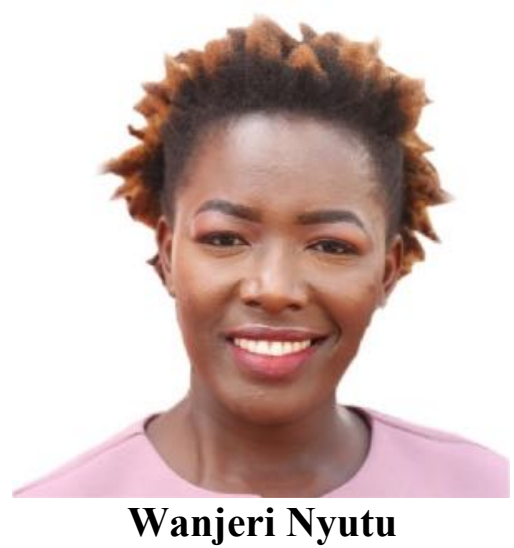

*Corresponding author email: nyutuvictoria@gmail.com

${ }^{1}$ Department of Food Science and Technology, Jomo Kenyatta University of Agriculture and Technology, Nairobi, Kenya

${ }^{2}$ Department of Human Nutrition Sciences, Jomo Kenyatta University of Agriculture and Technology, Nairobi, Kenya

${ }^{3}$ International Nutrition Working Group, Institute of Nutritional Sciences, Justus-LiebigUniversity Giessen, Germany 


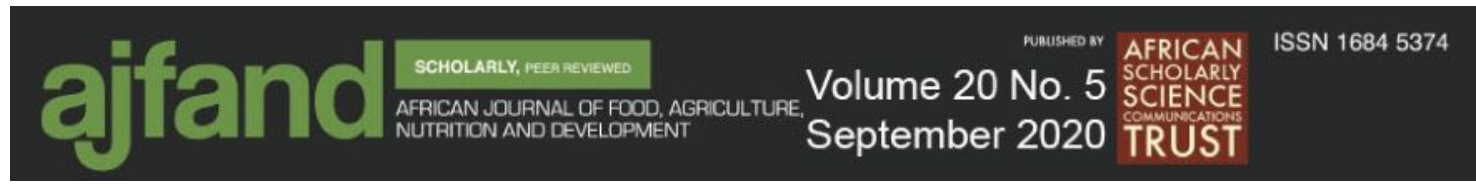

\begin{abstract}
Baobab (Adansonia digitata L.) is an indigenous fruit tree (IFT) that grows in several dry parts of Kenya such as Kitui and Kilifi counties. It plays a key role in dietary diversification thus contributing to food and nutrition security. This tree is adaptable to adverse climatic conditions such as droughts and floods, which are common in these counties. Consequently, it acts as a source of income and a food buffer during disasters. This study evaluated the role baobab plays during food emergencies. The study employed a cross-sectional design where 216 household heads were interviewed through structured interviews. Data were analysed using SPSS version 24. Baobab was available during lean seasons and was used as a source of food and income. Respondents mainly consumed baobab fresh fruits without any processing (94\%). During times of scarcity when there was nothing else available to eat. About $33.3 \%$ used baobab pulp to make porridge while $16.7 \%$ made a hard gruel (ugali). Drinks and candies, commonly called 'mabuyu sweets', accounted for $41.2 \%$ and $28.7 \%$, respectively. In Kilifi, baobab pulp was mixed with coconut milk to be used as an accompaniment to ugali $(34.3 \%)$. About two thirds $(60.7 \%)$ of the respondents collected and stored whole baobab fruits for use during lean seasons. Baobab pulp was sold by $34.7 \%$ of the respondents and the income was used to buy food $(45.3 \%)$, education $(22.7 \%)$ and for healthcare $(13.3 \%)$. This study indicates that baobab fruit and pulp was available and accessible during lean seasons. The baobab pulp was mainly consumed without any processing as a snack. It also used to make different foods at times when many other foods were not available. Households sold baobab fruits to augment their income. Promotion of baobab products could bring better incomes and improve the nutritional status of communities in baobab growing areas and helps to overcome food insecurity in emergencies.
\end{abstract}

Key words: lean seasons, baobab products, income, food insecurity, coping 


\section{INTRODUCTION}

Indigenous fruit trees (IFTs) play an important role in rural livelihoods [1]. Many communities living in semi-arid areas of Africa rely on IFTs to diversify their diets, especially during emergencies. Emergencies are urgent situations with clear evidence that the events, which have occurred result in human suffering or imminently threaten human lives or livelihoods and for which governments lack immediate means to remedy. The events causing the emergency can be calamities such as famine, floods, earthquakes or infestation from locusts. Human-made emergencies, such as civil war, lead to the displacement of people and suffering. Economic shocks impact vulnerable populations that are unable to access food because of a market failure leading to food emergencies [2].

Kenya is generally a drought-prone country with $80 \%$ of the land area being arid or semiarid. Climate changes and lack of proper harnessing of natural resources, has increased the number of people affected by recurrent and prolonged drought witnessed in the recent past. Frequent prolonged drought episodes have been the single most disastrous natural hazard leading to death, hunger and disease among the vulnerable communities [3]. For instance, in 2018, 3.4 million people in 23 out of 47 counties were affected by the drought experienced in the country as a result of failed rainfall for two consecutive years. It was one of the worst humanitarian crises in Kenya in almost a decade that lead to the declaration of the drought as a national disaster by the government [3].

The African Baobab (Adansonia digitata L.) is from the Bombacaceae family. It grows naturally in the semi-arid regions of tropical Africa. It is one of the most useful indigenous tree types for both animals and humans. The species contributes to rural income for medicinal and nourishment purposes [4]. The pulp can be consumed in many forms but is mainly mixed with maize, sorghum, millet or water to make a beverage. Baobab leaves can also be used as leafy vegetables or can be milled, sun-dried or shadedried then milled and passed through a sieve to give a green powder that is used to flavour sauces by many households $[5,6]$. Past studies have shown that the pulp has high amounts of vitamin C, enough to meet $80 \%$ to $100 \%$ of the daily recommended intake of pregnant women by consuming $40 \mathrm{~g}$ per day. The leaves have high amounts of calcium ranging from $307-2640 \mathrm{mg} / 100 \mathrm{~g} \mathrm{dw}$ and quality protein with a chemical score of $0.81[5,7]$.

Baobab products can be used to bring economic prosperity to the rural poor if they are well developed [1]. In addressing problems of food and nutrition insecurity, it is important to consider agricultural biodiversity, but this has not been the case. Biodiversity is important in safeguarding against hunger, providing nutrients and strengthening local food systems while enhancing environmental sustainability. Naturally occurring IFTs could be used in emergency food strategies because when natural resources are sustainably managed, they strengthen livelihoods and ensure good nutrition and health [8]. Throughout Africa, a majority of communities are dependent on IFTs for their livelihoods $[9,10]$. Utilization of IFT fruits has been shown to substantially increase rural income and open up employment opportunities [11]. There is a need to determine the contribution of baobab products to household incomes and diets and describe the extent of use at the household level (commercial and domestic use). 


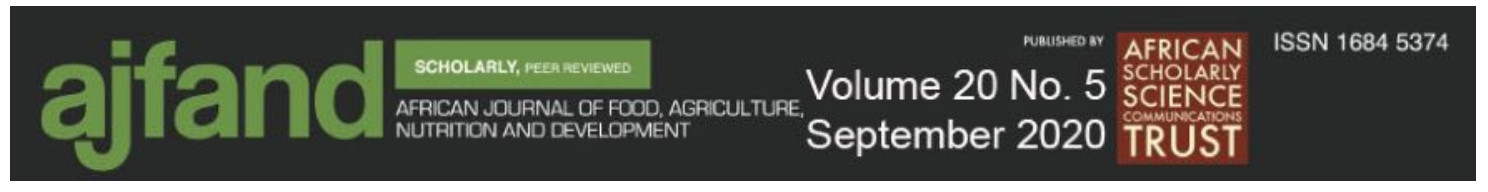

Consumption of wild fruits as food varied among different ethnic communities and regions in Kenya [12]. This study was conducted among different ethnic groups in Kenya to assess the accessibility and availability of baobab to households as food during lean seasons of food availability, and its contribution to household food security, especially during food emergencies.

\section{MATERIALS AND METHODS}

\section{Study Area}

The study was conducted in Kilifi and Kitui Counties. These counties receive an average of $550-850 \mathrm{~mm}$ of rainfall per year and have high poverty index levels of above $60 \%$. $[3]$.

According to the Kenya Food Security Steering Group (KFSSG), poor rainfall has been a major driver of food insecurity in both counties. Most of the regions were classified as stressed in terms of food security, while some pockets were in crisis phase and required intervention [13].

The two counties were purposively chosen as baobab grows in some of their constituencies and because they are part of the semi-arid areas where food emergencies are likely to occur.

\section{METHODOLOGY}

Five study sites were selected based on the baobab 'belt' occurrence in the two counties. Kitui South, Kitui East, Kilifi North, Kilifi South and Ganze constituencies were selected using multi-stage stratified sampling procedures. Thirteen wards, three in each constituency, were selected except in Ganze constituency where only one ward was selected. Since a comprehensive list of households in the wards was not available at the sub-county administrator offices, a random procedure was used to select households depending on their availability. The households selected were grouped into 9 households to form a village cluster and 16 households to form a ward cluster. In total, 216 household heads were interviewed in both counties.

Structured researcher administrated interviews were conducted using the Open data kit 1 (ODK) tool version 1.6.1 on Lenovo pad tablet model number TB3-710F essential android version 5.0. Written consent was obtained from the respondents. Data were collected in July in Kitui County and November 2017 in Kilifi, which was the harvest season respectively.

Baobab pulp consumption was measured from the average weight of whole baobab fruits depending on the average weight in each county. The following mean weights were used: Kilifi whole fruits were $358.6 \mathrm{~g}$ per fruit with pulp content $12.1 \%$, and Kitui County had smaller fruits of $134.6 \mathrm{~g}$ and higher pulp of $13.3 \%$. 


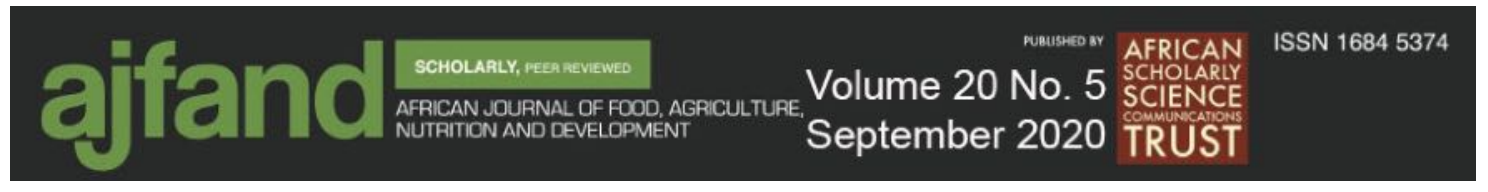

The following formula was used to determine the amount of baobab pulp consumed per household during one meal:

No. of fruits used $\times$ mean weight

of one fruit $\times$ percentage of pulp

The total income from baobab product sales was reported in Kenya Shillings.

\section{Data Analysis}

Data on baobab product availability and use were quantitatively analysed using SPSS version 24 IBM Corp. 2016. Descriptive statistics were done to report on the availability of baobab and its uses. A line graph was plotted to show the availability of baobab and lean seasons. Chi-square test was performed for differences in baobab consumption and mean amounts of income between the two counties.

\section{Ethical Consideration}

A research permit was given by the National Commission for Research and Technology (NACOSTI) Ref No. NACOSTI/P/17/80886/16355 and an Ethical clearance from Mount Kenya University Ref. no. MKU/ERC/0391.

\section{RESULTS AND DISCUSSION}

\section{Social Demographic Characteristics}

In Kitui and Kilifi Counties, a total of 216 respondents were interviewed, 108 respondents in each county. The average household size was $7 \pm 2.13$ in Kitui County and $9 \pm 3.59$ in Kilifi County. In Kitui County, nearly half (45.5\%) of the household heads had attained upper primary education, while $24.2 \%$ managed to lower primary and only $9 \%$ had no formal schooling. In Kilifi County, $46.8 \%$ household heads had an upper primary education, $12.8 \%$ had completed high school, and $1.8 \%$ had some form of tertiary education while $31.2 \%$ had no formal education. The main occupation for most respondents in Kitui County was mixed farming (37\%), while $27 \%$ engaged in casual labour and $16 \%$ had small businesses. In Kilifi County, 25.2\% were practising crop farming, about $16.8 \%$ were mixed farmers, and $23.4 \%$ were casual labourers while those operating small businesses were $16.8 \%$ as shown in Table 1.

\section{Baobab processing, use and storage}

The main processing done in both counties according to household heads was cracking dry fruits $(95.4 \%)$ in Kilifi and $(92.6 \%)$ in Kitui. Pounding to extract baobab pulp was done by $17.6 \%$ of households while oil extraction from seeds was done by $2.8 \%$ of interviewees in Kitui County. During lean seasons, baobab seeds were roasted by $32.4 \%$ of respondents in Kitui County and $11 \%$ of respondents in Kilifi County. Some respondents $(54.2 \%)$ stored baobab fruits collected for future use in Kitui compared to about $69.4 \%$ of respondents in Kilifi county. Most of the fruits collected were stored whole $(48.2 \%)$ by interviewees in Kitui County while $28.7 \%$ of respondents stored the fruits whole in Kilifi county. The dried whole fruits stored were used in the preparation of different meals and snacks. Two respondents, however, kept the baobab to wait for better prices once the harvest period was over. The baobab fruits (uncrushed) have a shelf 


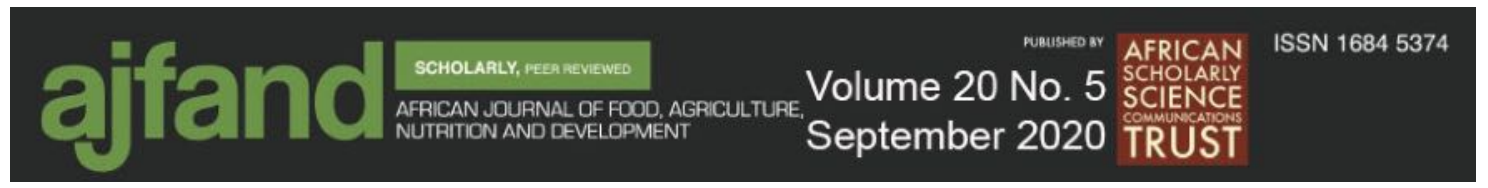

life of one (1) year [1]. The only pre-storage processing was drying to prevent infestation by termites in both counties. Baobab processing could increase incomes and acceptability among adults through oil pressing from seeds that are otherwise thrown after eating the pulp [7]. Adding value to baobab can significantly increase incomes for communities endowed with the resource.

Baobab pulp is used in many ways, the most common being eating the fresh fruit, adding it to porridge or soups, making gruels, ice cream, making juice and candies (mabuyu sweets) as shown in Figure 1.

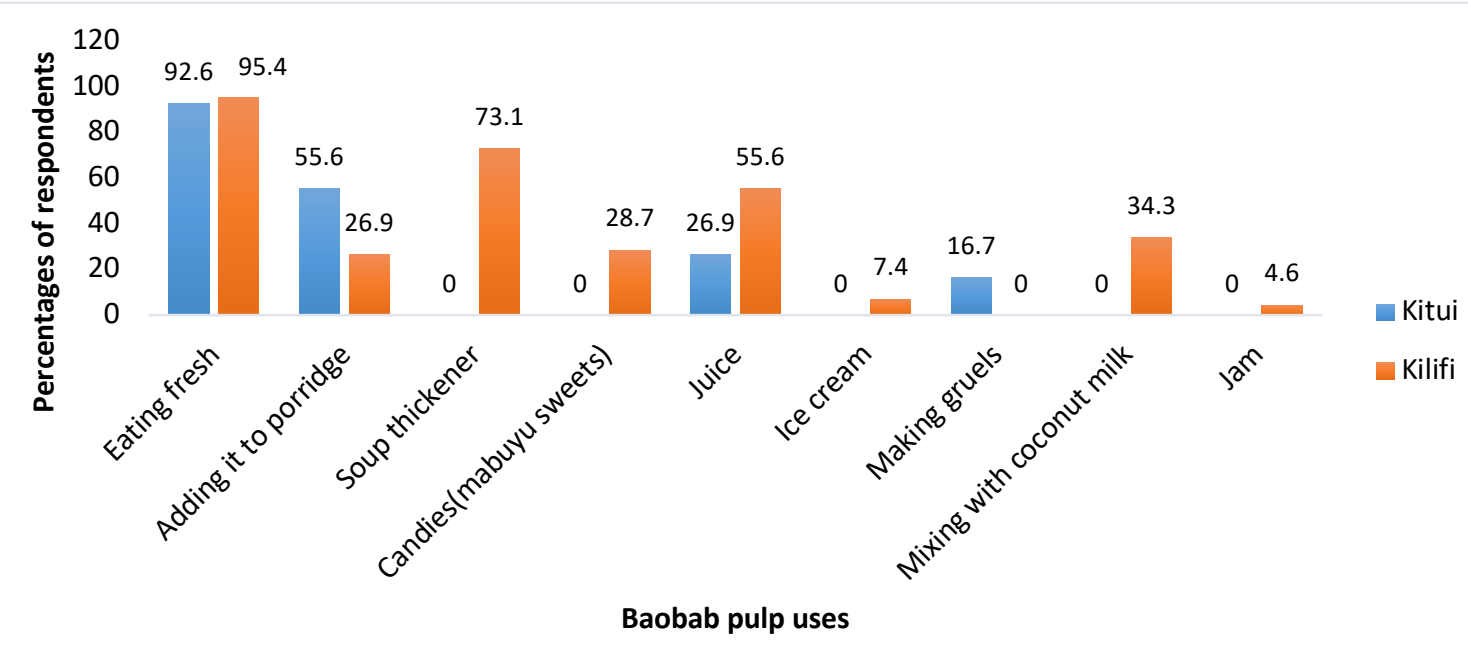

Figure 1: Various uses of baobab pulp

Additionally, non-food uses of baobab included the making of crafts such as ropes, firewood, rat traps, mosquito repellent and medicinal purposes. Respondents made ropes from baobab bark (10.2\%) in Kitui County and (10.2\%) in Kilifi. Baobab fruit shells were only used in Kilifi County as firewood (7.4\%). Less than two percent of respondents in both counties used baobab parts as fodder for their livestock. Baobab fruit shells were used by household heads to make traps for wild rats (24.1\%), a delicacy in Kilifi County. About $5.6 \%$ of respondents in Kilifi County cut baobab branches or trunks to use them as mushroom growth culture.

The crafts were of significant importance. The traps contributed to food and nutrition security and diet diversification. Barks used to make ropes for domestic animals also contributed to households' savings as respondents saved their earnings by using this available resource as opposed to buying nylon or sisal ropes from the market. Making crafts from baobab shells is an underutilised potential in the two regions. It can be an income source especially in Kilifi given its location where tourists visit. The fruit shells were also used as firewood, therefore reducing deforestation and consequently delaying food emergencies. Communities in Kitui also used the short baobab trees as a store for fodder protecting it from insect damage and rotting. The erecting of beehives on baobab trees in Kitui County also contributed to incomes and food security from sale and consumption of honey. 


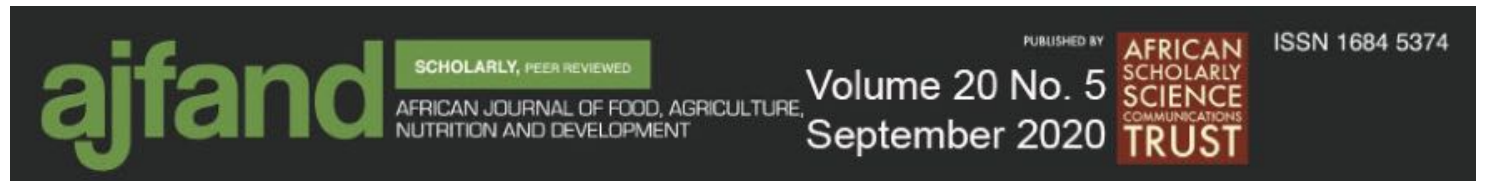

\section{Utilization of baobab as food during the hunger period}

\section{Accessibility and availability of baobab}

In Kitui County, the household heads (81.5\%) owned an average of $4.6 \pm 6.4$ baobab trees. The majority (92\%) of these respondents harvested baobab products. About $18.5 \%$ of respondents did not own any tree but had access to baobab trees belonging to the neighbours or extended family. In Kilifi County, about $57.4 \%$ of the households owned an average of $8.2 \pm 21.1$ baobab trees, but only $53.7 \%$ of respondents harvested baobab pulp. About 3.7\% interviewees had no access to baobab trees, while $38.9 \%$ had access to baobab through neighbours' trees or from community land and nearby lands.

Different parts of the baobab were harvested for food purposes and sale (Table 2). These parts include pulp, leaves, fruit shells, stem and bark were used for other domestic uses. In Kitui County, majority of the respondents (75\%) harvested baobab pulp only and none of the respondents in Kitui harvested baobab leaves. About $43.5 \%$ of households in Kilifi harvested leaves from young baobab plants or young leaves from mature fruit-bearing trees. About $10.2 \%$ of respondents in Kitui County made ropes from baobab barks compared to $9.43 \%$ in Kilifi County. The stems of broken baobab tree branches were used as a mushroom growth culture by $5.6 \%$ of respondents in Kilifi County. Other uses are listed in Table 2.

From the study, it is evident that baobab was part of meals in Kitui and Kilifi counties. Respondents in Kitui County used large amounts of baobab pulp for their daily needs in making porridge and mixing with starch depending on taste preference to make gruels during lean seasons. This confirms the assertion that forest foods help maintain household nutrition in many populations [9]. During the 1984 and 2011 major droughts in Kenya [3], key informants confirmed that baobab fruits were the only edible plants available at the time for most people. Households would grind seeds or roast them as there was no starch to accompany the pulp at those times. The prolonged drought and eating of baobab fruits during those periods, however, brought a negative perception that baobab caused weak bones, associated with poverty, tingling sensations, and other perceptions in Kitui County. This study and another study done in Kenya recommended that domestication, coupled with raising awareness on the value of baobab would help improve perception in rural communities from 'food for children' to 'valuable fruits for health and wealth' [8]. Baobab is used as a coping strategy when disasters strike and also during pre-harvest periods of annual staples, which is characterized by food shortage 'hunger gaps' [8], especially in Kitui County.

\section{Amount of baobab pulp consumed}

There was a significant difference in the average consumption of baobab between the two counties $(p<0.0001)$. In Kilifi and Kitui counties the average consumption of baobab pulp was $361.3 \mathrm{~g}$ and $1297 \mathrm{~g}$, respectively. Fruit consumption in sub-Saharan Africa is below the daily recommended amount [9]. As such, baobab pulp, which has high amounts of vitamins and minerals, comes in handy especially during lean seasons when people do not have the luxury of buying fruits. Their high sugar content makes them an important source of energy during disasters and times of food shortages [9]. There was, however, a challenge in participants being unable to say exact amounts of fruits they 


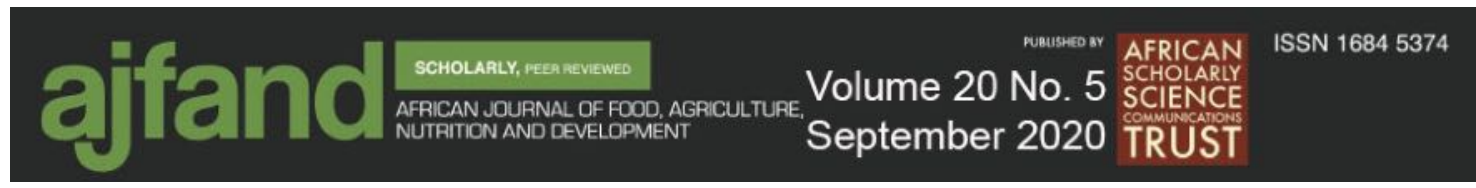

consumed or frequency because of the perception that only poor people and children take baobab fruits or the fact that they did not consume them regularly.

\section{Methods of Harvesting Baobab Fruits}

The most preferred mode of harvesting was collecting fallen fruits from the ground as shown in table 3 , thus limiting the intake and sale of baobab to the nature of the tree. For instance, the African baobab is huge and round, reaching a height of $18-25 \mathrm{~m}$, the bark is smooth [7]; climbing the tree is a challenge and requires skill. Most of the respondents would wait for the fruits to fall by themselves and collect them as opposed to scaling the tree. Respondents placed beehives on baobab trees, thus making it unsafe to climb. Women who are mostly in charge of meal preparations would be discouraged from utilizing the fruits and leaves due to the height. Therefore, grafting would make harvesting of fruits easier and accessible. Grafted baobab occupied less space and would discourage communities from cutting them down. It could also make some fruits sweeter and hence, drive up an increase in its consumption leading to better health outcomes.

\section{Baobab maturity and food security}

The baobab tree fruits once a year. The duration of harvesting depended on the amount of fruit yield. In both counties, baobab fruits were harvested for an average of three (3) months. Baobab fruits were available during months of hunger in Kitui County unlike in Kilifi County as shown in Figures $2 \mathrm{a}$ and $\mathrm{b}$.

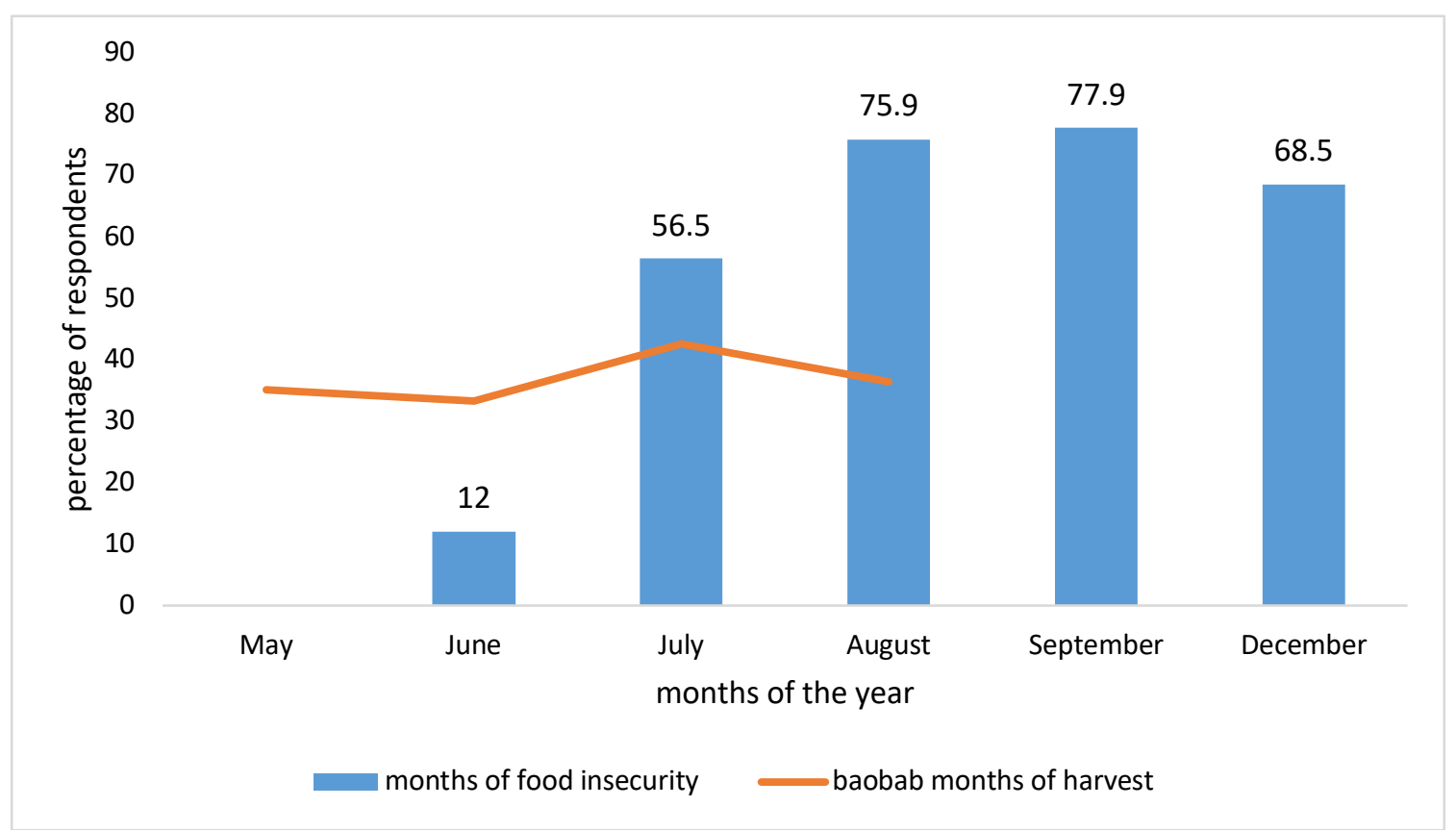

Figure 2a: Baobab Fruits availability in Kitui County and lean seasons 

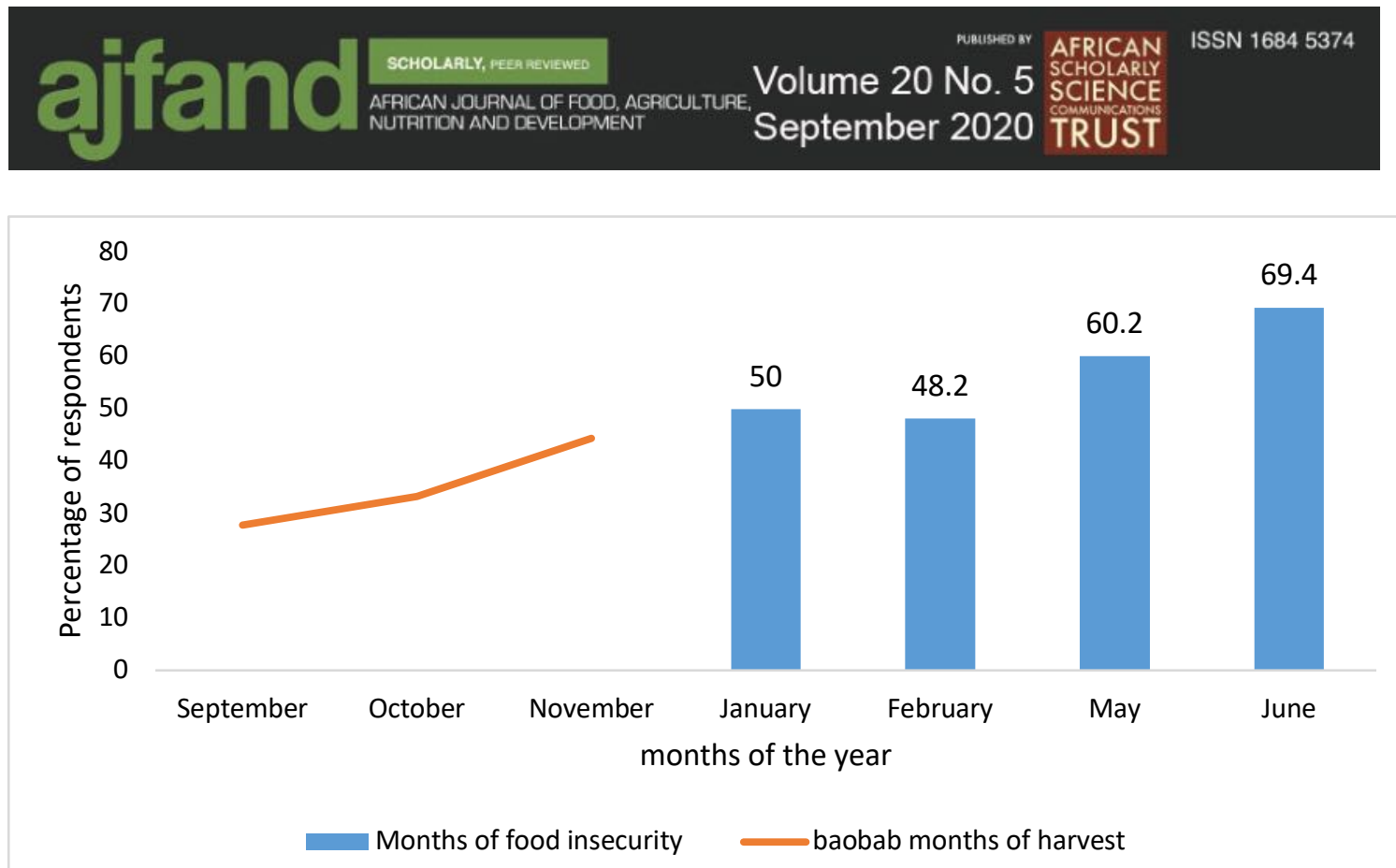

Figure 2b: Baobab Fruit availability in Kilifi County and lean seasons

In Kilifi County, the main months of baobab fruit availability with the highest number of respondents confirming the same were September (27.8\%), October (33.3\%) and November (44.4\%), while in Kitui County, the months with most respondents confirming that baobab fruits were available were May (35.2\%), June (33.3\%) and July (42.6\%). However, with regards to baobab leaves, in Kitui County, none of the respondents harvested baobab leaves even for livestock. In Kilifi County, baobab leaves were used by less than half of the respondents. The frequency of baobab leaf intake by interviewees was mostly one to three times a month $(25 \%)$, less than once a month $(6.5 \%)$ and two to three times a month $(5.6 \%)$.

In both counties, the sprouting of baobab leaves indicated that rains were about to come according to key informants in both counties. As such, people would estimate the time it would take for the rains and could accurately time the planting leading to lower losses if rains did not come on time. Others said that during the years that baobab produced a lot of fruits, what followed was starvation due to lack of rain as Kenya heavily relies on rain for agriculture. The theories may not have been scientifically proven; however, if there is no sensitization on the importance of crop diversity, such knowledge will be lost over time yet we have not yet fully understood the benefits of Indigenous fruit trees such as baobab [15].

\section{Baobab as a source of income and its role in the months of food insecurity}

The months of food insecurity reported by the respondents were July (56.5\%), August (75.9\%), September (77.8\%) and December (68.5\%) in Kitui County and January (50\%), February (48.2\%), May (60.2\%) and June (69.4\%) in Kilifi County. These months coincided with the maturity period of baobab fruits. Thus, baobab leaves and non-food baobab products, such as ropes, rat traps and firewood, were used during these months, especially as a source of energy for cooking. Some respondents reported having sold baobab, either as a whole fruit or pulp or processed products such as candies, or what is commonly referred to as mabuyu. For instance, in Kitui County baobab was sold by mothers (15.7\%), children (9.3\%) and 1.1\% was sold by fathers. In Kilifi County, $18.5 \%$ 


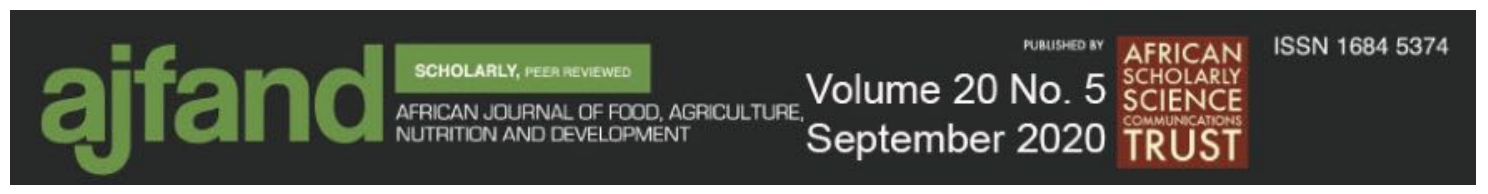

of fathers sold baobab, $13 \%$ was sold by mothers while $2.8 \%$ was sold by children. In Kitui County, the baobab fruit was sold in pulp form while in Kilifi it was sold per bag of whole baobab fruits, per baobab tree (all of the baobab tree yield) or in baobab pulp form. In Kilifi County, the average amount of money earned from baobab fruits or pulp sale was 10.5 USD, while in Kitui the average amount of money was 10.65 USD. There was no significant difference in average incomes between the two counties $p=0.729$.

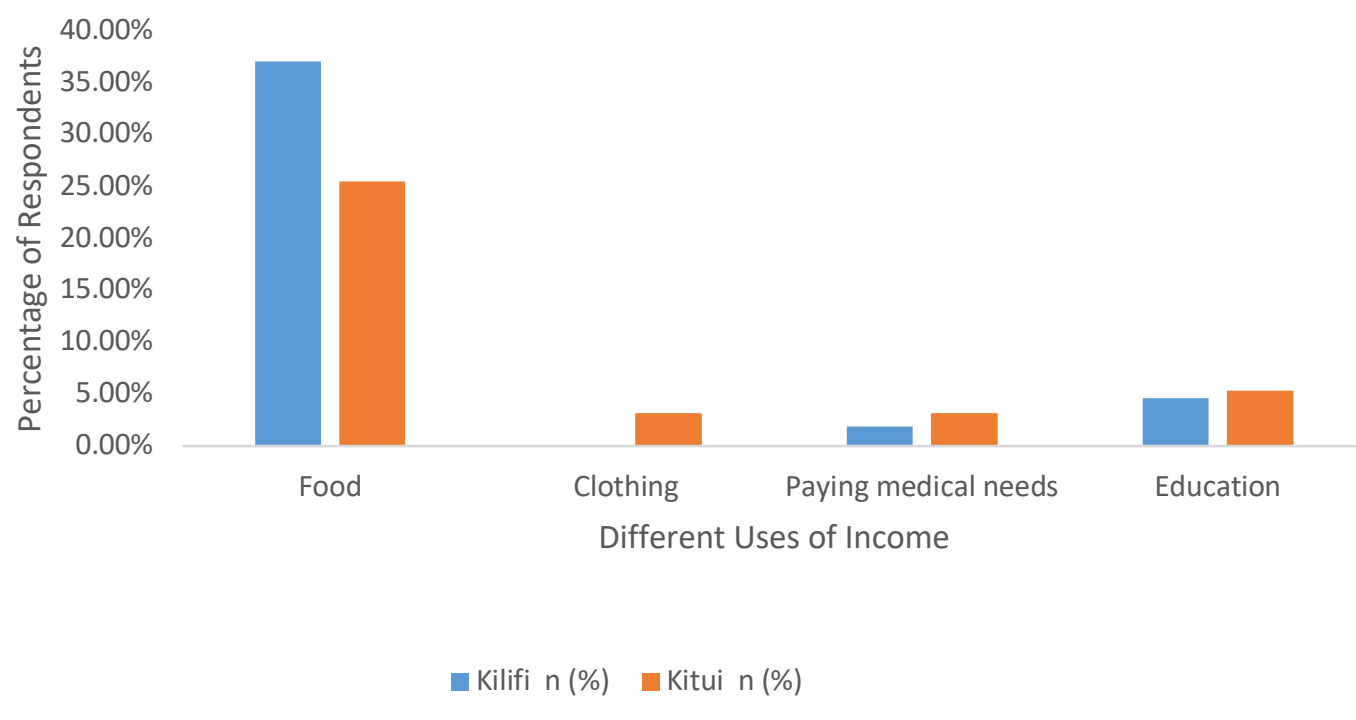

Figure 3: Uses of baobab earnings

When baobab was sold, a bulk of the money went into buying food as shown in figure 3 . While baobab fruit was a source of income for more than half of the respondents, the money received from sales was little compared to the price in the urban markets. For respondents in Kitui, the average amount of money per kilo of pulp was 0.093 USD. Baobab in Kitui was sold in Kilograms and already shelled unlike in Kilifi where a buyer would hire a skilled climber who would do the felling of the fruits and then shell them. Sometimes it would be sold in bags but most of the times it would be per tree regardless of the number of fruits. The amounts were also low as the highest amount per tree would be 1.86 USD for each tree or an average of 7.44 USD for a sack of uncracked fruit. All respondents who were involved in the study agreed that though there was some income from baobab, it was not sufficient to solve food insecurity problems; nevertheless, the income helped to supplement what was available. A kilo of maize, which is the staple food in Kenya, goes for between (one) 1 USD to 1.5 USD and as such it would help a family have a meal for a night. Research conducted in Kenya ranked baobab as number two in priority of indigenous fruit trees because of its potential as a source of income and food [1]. 


\section{Challenges limiting use and sale of baobab products}

Multiple factors hinder the maximum utilization of baobab in Kitui, among them being the perception that it is food for children (porridge) and not adults (47.6\%), the perception that it causes knee joint or health problems $(31.7 \%)$, poor rainfall causing poor harvests (39.7\%), baobab tree was believed to suck all the water and nothing grew at its base $(31.7 \%)$, the perception that it is for the poor $(31.7 \%)$, and others $(23.8 \%)$ said that it is too much trouble before one can get a kilo of baobab pulp. Other factors were that there are beehives on the baobab trees, (9.5\%) making it difficult for them to be accessed, losses due to invasion by monkeys $(6.3 \%)$, few trees with little economic benefit $(19 \%)$ and that it fruits only once a year (3.2\%). In Kilifi County, the main challenges were lack of rain leading to poor harvests $(27.5 \%)$, baobab producing only once a year, $(21.6 \%)$, no market $(21.6 \%)$, poor pricing by middlemen $(19.6 \%)$, and that its value is yet to be seen $(19.6 \%)$.

There has been a declining number of baobab trees [1] per household, mostly as a result of lack of knowledge on uses, commercialization, and negative cultural perceptions associated with the baobab tree as listed in Table 4. In Kitui County, it was believed to cause dryness by sucking all the water because its lateral roots may reach over $100 \mathrm{~m}$ [14], and as such, they would not be allowed near homesteads. In Kilifi County, there are beliefs that the trees harbour 'devils 'and as such are not allowed near the homesteads. The problem has further been complicated by urbanization leading to change of diets, deforestation, and land subdivision due to increasing population. With Africa facing serious threats of food insecurity, there is an obvious need to integrate crops with high nutritional value, preserve the biodiversity in the areas, and include locals' coping strategies and indigenous knowledge while being sensitive to the cultural beliefs of communities [9].

\section{CONCLUSION}

Baobab fruits have a role to play during food emergencies in both counties as it was used as a substitute for unavailable foods during emergencies such as milk and green vegetables. It also helped supplement income when sold. Baobab leaves made other wild leaves palatable as they were used to soften them, thus contributing to diet diversification and nutrition security. Other parts such as barks, branches, fruit shells, contribute to the welfare of households, income and food security as they were used for making ropes, setting beehives, preparing growth culture, rat traps and bush meat traps.

The full potential of baobab fruits was not exploited as most were left to go to waste. Only a few households stored baobab fruits for later use. Only a few leaves were used in mixing with other vegetables. There is, therefore, a need to sensitize the community on value addition of baobab fruits and leaves as they are of high nutritional value and alternative foods during food scarcity. The health problems perceived to be caused by baobab pulp need to be investigated further. 


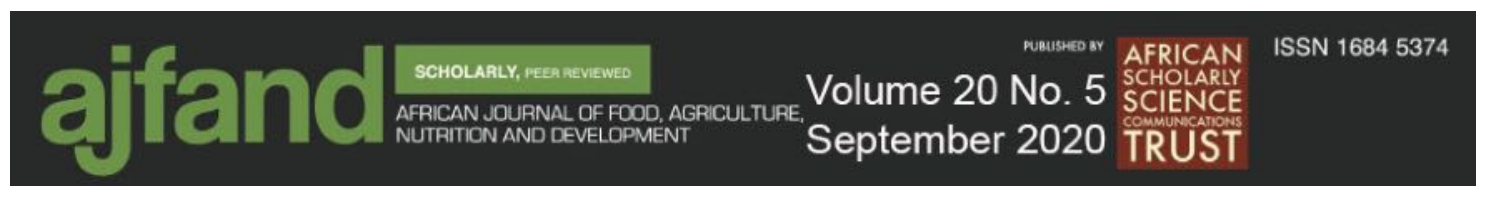

\section{ACKNOWLEDGEMENTS}

The authors would like to thank the County Commissioners of Kilifi and Kitui counties for granting permission to carry out the study, The County Executive Committee members of Agriculture and Health and Sanitation in the respective counties, and Kenya National Bureau of Statistics for demographic information provided. The authors are also thankful to all the participants for agreeing to participate in the study. We further thank the Germany Federal Ministry of Food and Agriculture (BMEL) under Grant funding code 2813FSNU07 for financial support, based on the decision of the parliament of the Federal Republic of Germany through the Federal Office of Agriculture and Food (BLE) as a component of the "Enhancing local food security and nutrition through promoting the use of baobab in rural communities in Eastern Africa" (also known as the BAOFOOD) Project. 


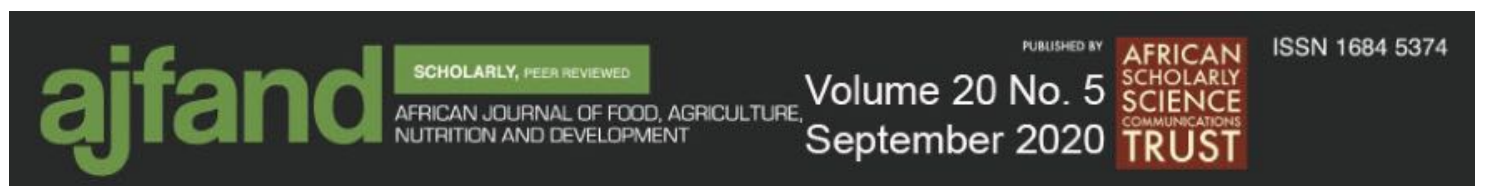

Table 1: Social Demographic characteristics of households in Kitui and Kilifi County

\begin{tabular}{lll}
\hline Demographic & $\begin{array}{l}\text { Kitui County } \\
\mathrm{n}(\%)\end{array}$ & $\begin{array}{l}\text { Kilifi County } \\
\mathrm{n}(\%)\end{array}$ \\
\hline Education level & $2(1.9 \%)$ & $2(1.9 \%)$ \\
Tertiary & $21(19.5 \%)$ & $14(12.8 \%)$ \\
High school & $49(45.5 \%)$ & $51(46.8 \%)$ \\
Upper primary & $26(24.2 \%)$ & $8(7.4 \%)$ \\
Lower primary & $10(9 \%)$ & $34(31.2 \%)$ \\
No formal education & & $18(16.8 \%)$ \\
Occupation & $40(37 \%)$ & $27(25.2 \%)$ \\
Mixed farming & 0 & $23.4 \%$ \\
Crop farming & $29(27 \%)$ & $18(16.8 \%)$ \\
Casual labourer & $17(16 \%)$ & \\
Small business & & \\
\hline
\end{tabular}

Table 2: Use of different baobab parts

\begin{tabular}{|c|c|c|c|c|c|c|c|c|}
\hline $\begin{array}{l}\text { Harvest } \\
\text { parts } \\
\text { and } \\
\text { Uses }\end{array}$ & $\begin{array}{l}\text { Pulp } \\
\mathrm{n}(\%)\end{array}$ & $\begin{array}{l}\text { Leaves } \\
\text { n (\%) }\end{array}$ & $\begin{array}{l}\text { Ropes } \\
\mathrm{n}(\%)\end{array}$ & $\begin{array}{l}\text { Firewood } \\
\mathrm{n}(\%)\end{array}$ & $\begin{array}{l}\text { Rat } \\
\text { traps } \\
\mathrm{n}(\%)\end{array}$ & $\begin{array}{l}\text { Mushroom } \\
\text { growth } \\
\text { culture } \\
\mathrm{n}(\%)\end{array}$ & $\begin{array}{l}\text { Mosquito } \\
\text { repellent } \\
\mathrm{n}(\%)\end{array}$ & $\begin{array}{l}\text { Medicinal/cultural } \\
\text { purposes } \\
\mathrm{n}(\%)\end{array}$ \\
\hline Kilifi & $62(57.4)$ & $45(41.7)$ & $11(10.2)$ & $8(7.4)$ & $28(25.9)$ & $6(5.6)$ & $1(0.93)$ & $3(2.8)$ \\
\hline Kitui & $81(75)$ & 0 & $11(10.9)$ & $4(3.7)$ & 0 & 0 & 0 & 0 \\
\hline
\end{tabular}


Table 3: Methods of baobab harvesting

\begin{tabular}{|c|c|c|}
\hline & $\begin{array}{c}\text { Kilifi } \\
\text { n } \\
(\%)\end{array}$ & $\begin{array}{c}\text { Kitui } \\
\text { n } \\
(\%)\end{array}$ \\
\hline Self-Climbing and picking & $\begin{array}{c}17 \\
(16.5 \%)\end{array}$ & $\begin{array}{c}22 \\
(25.3 \%)\end{array}$ \\
\hline $\begin{array}{l}\text { Skilled personnel climbing } \\
\text { and picking }\end{array}$ & $\begin{array}{c}24 \\
(23.3 \%)\end{array}$ & $\begin{array}{c}15 \\
(17.2 \%)\end{array}$ \\
\hline Using sticks to hit fruits & $\begin{array}{c}41 \\
(41 \%)\end{array}$ & $\begin{array}{c}49 \\
(56.3 \%)\end{array}$ \\
\hline $\begin{array}{l}\text { Collecting fallen fruits } \\
\text { from the ground }\end{array}$ & $\begin{array}{c}49 \\
(48 \%)\end{array}$ & $\begin{array}{c}56 \\
(64.4 \%)\end{array}$ \\
\hline
\end{tabular}




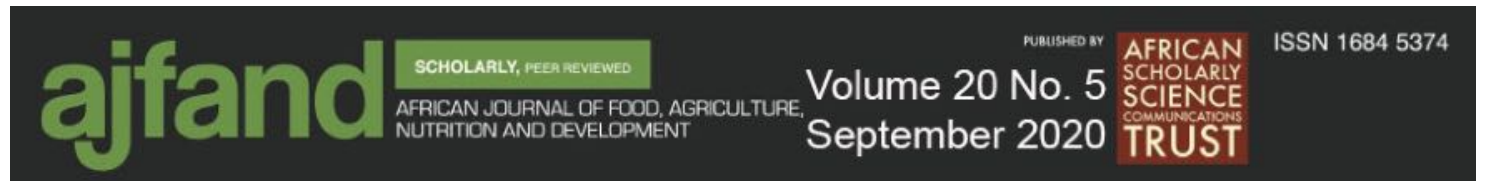

Table 4: Reasons for Limited Baobab Products Use and Sale

\begin{tabular}{lll}
\hline Reasons for limited use & $\begin{array}{l}\text { Kitui county } \\
\text { n (\%) }\end{array}$ & $\begin{array}{l}\text { Kilifi county } \\
\text { n (\%) }\end{array}$ \\
\hline Health problems (joint & $20(31.7 \%)$ & 0 \\
pains, tiredness, fatigue, & & \\
tickling of feet \& mouth & & \\
sores) & $25(39.7 \%)$ & $14(27.5 \%)$ \\
Poor rainfall & $30(47.6 \%)$ & 0 \\
Food for children & $20(31.7 \%)$ & 0 \\
Food for poor & $15(23.8 \%)$ & 0 \\
Too much work and & & \\
trouble in accessing fruits & & 0 \\
Erected beehives on tree & $6(9.5 \%)$ & 0 \\
Invasion by monkeys & $4(6.3 \%)$ & 0 \\
Few trees & $12(19 \%)$ & $11(21.6 \%)$ \\
Tree only fruits once & $2(3.2 \%)$ & $10(19.6 \%)$ \\
No market & 0 & $10(19.6 \%)$ \\
Middlemen & 0 & $10(19.6 \%)$ \\
No value & 0 & 0 \\
Sucks all water and & $20(31.7 \%)$ & \\
nothing grows at its base & & \\
\hline
\end{tabular}




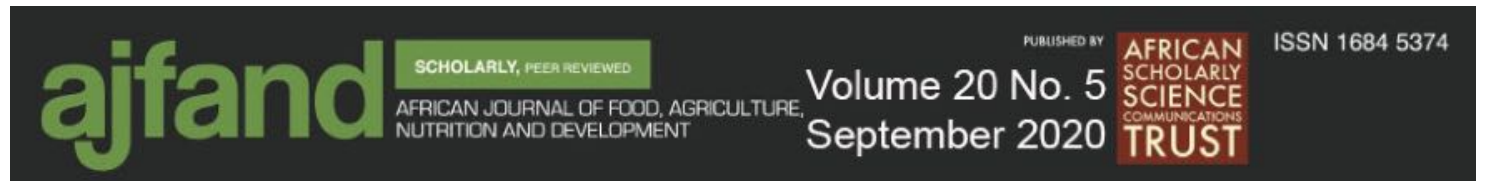

\section{REFERENCES}

1. Chikamai B, Eyog-Matig $\mathbf{O}$ and M Mbogga Review and Appraisal on the Status of Indigenous Fruits in Eastern Africa. A Report Prepared for IPGRI-SAFORGEN in the Framework of AFREA/FORNESSA 2004.

2. WFP. Definition of Emergencies. WFP, 2005.

3. King-Okumu C, Orindi VA and L Lekalkuli Drought management in the drylands of Kenya: what have we learned? In Current Directions in Water Scarcity Research 2019; 2: 277-294). Elsevier.

4. Donatien K A Review of Baobab (Adansonia digitata) Products: Effect of Processing Techniques, Medicinal Properties and Uses. African J Food Sci. 2011; 5.

5. Chadare FJ Baobab (Adansonia digitata L.) Foods from Benin: Composition, Processing and Quality. 2010: 182.

6. Chadare FJ, Linnemann AR, Hounhouigan JD, Nout MJR, and MAJS Van Boekel Baobab Food Products: A Review on their Composition and Nutritional Value. Crit Rev Food Sci Nutr. 2008; 49: 254-74.

7. Sidibe M, Williams JT, Hughes A, Haq $\mathbf{N}$ and RW Smith Baobab (Adansonia digitata L.). International Centre for Under-Utilized Crops, 2002: 105.

8. Fanzo J, Hunter D, Borelli T and F Mattei Diversifying Food And Diets: Using Agricultural Biodiversity To Improve Nutrition And Health. Earthscan For Routledge 2013: 400.

9. Vinceti B, Ickowitz A, Powell B, Kehlenbeck K, Termote C, Cogill B and D Hunter The Contributions of Forest Foods to Sustainable Diets. Unasylva. 2013; 64: 54-64.

10. Gebauer J, Adam YO, Darr D, Eltahir MES, Fadl KEM, Fernsebner G, Frei M, Habte T-Y, Hammer K, Hunsche M, Johnson H, Kehlenbeck K, Kordofani M, Krawinkel M, Kugler F, Luedeling E, Mahmoud TE, Maina A, Mithofer D, Munthali CRY, Noga G, North R, Owino WO, Prinz K, Rimberia FK, Saied A, Sanchez AC, Schuring M, Sennhenn A, Spath MA, Taha MEN, Triebel A, Winchern F, Wiehle M And N Wrage-Monnig Africa's Wooden Elephant: The Baobab Tree (Adansonia Digitata L.) in Sudan and Kenya. Genetic Resources and Crop Evolution. 2016; 63: 377-99.

11. Venter SM and ETF Witkowski Fruits Of Our Labour: Contribution of Commercial Baobab (Adansonia Digitata L.) Fruit Harvesting to The Livelihoods of Marginalized People in Northern Venda, South Africa. 2013;159-72. 


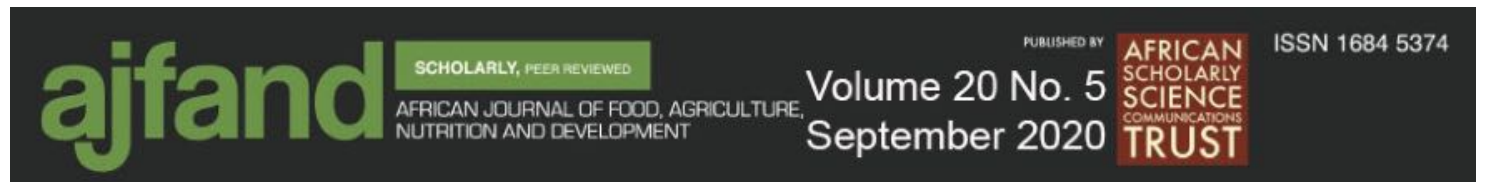

12. Patrick MM, Grace WN and HSK Christine Traditional Food Plants of Kenya. Kenya Resource Centre for Indigenous Knowledge. National Museums of Kenya, 1999.

13. KFSSG. Government of Kenya the 2016 Short Rains Season Assessment Report. Kenya Food Security Steering Group, Kenya, 2017.

14. Wickens GE The Baobab: Africa’s Upside-Down. JSTOR. 2017; 37: 173-209.

15. Feyssa DH, Njoka JT, Asfaw $Z$ and MM Nyangito Seasonal availability and consumption of wild edible plants in semiarid Ethiopia: Implications to food security and climate change adaptation. J Hortic For. 2011; 3: 138-149. 